\title{
Variation in early developmental stages in two populations of an intertidal crab, Neohelice (Chasmagnathus) granulata
}

\author{
Claudia C. Bas · Eduardo D. Spivak • \\ Klaus Anger
}

Received: 7 January 2008/Revised: 1 August 2008/ Accepted: 5 August 2008/Published online: 3 September 2008

(C) Springer-Verlag and AWI 2008

\begin{abstract}
Duration of embryonic development, egg size, larval size at hatching, and starvation tolerance of the first zoeal stage were studied in an intertidal crab from the southwestern Atlantic, Neohelice (formerly Chasmagnathus) granulata. These reproductive traits were quantified comparing (a) two populations living in ecologically contrasting coastal habitats in Argentina, a brackish lagoon, Mar Chiquita, MC vs. an open marine habitat near San Antonio, Patagonia, SA, (b) beginning vs. end of the reproductive season, and (c) two temperatures during egg development (18 vs. $27^{\circ} \mathrm{C}$ ). Eggs in an early stage of embryonic development were in both populations larger at the beginning than at the end of the season, and were consistently larger in the SA population. These size differences persisted through larval hatching, independent of the temperature during embryogenesis. At $18^{\circ} \mathrm{C}$, eggs produced at the beginning of the season developed in both populations more rapidly than those from the end of the reproductive season, while the opposite trend was observed at $27^{\circ} \mathrm{C}$. The stage duration of the zoea I was in both populations shorter at the beginning as compared to the end of the season. The nutritional flexibility of the zoea I stage was compared using as indices the point-of-reserve-saturation
\end{abstract}

Communicated by H.-D. Franke.

C. C. Bas $(\bowtie) \cdot$ E. D. Spivak

Facultad de Ciencias Exactas y Naturales,

Departamento de Biología, Universidad de Mar del Plata,

Casilla de Correo 1245, 7600 Mar del Plata, Argentina

e-mail: ccbas@mdp.edu.ar

\section{K. Anger}

Biologische Anstalt Helgoland,

Stiftung Alfred-Wegener-Institut für Polar- und

Meeresforschung, Meeresstation, 27498 Helgoland, Germany
$\left(\mathrm{PRS}_{50}\right)$ and the point-of-no-return $\left(\mathrm{PNR}_{50}\right)$. The $\mathrm{PRS}_{50}$ was consistently lower in larvae from SA than in those from MC. In the MC population, this index was lower at the beginning than at the end of the season, while no significant seasonal difference was observed in larvae from $\mathrm{SA}$. The $\mathrm{PNR}_{50}$ varied between temperatures of embryonic development and populations, showing also significant interactions between all three factors. The $\mathrm{PRS}_{50}$ was on average lower, and the $\mathrm{PNR}_{50}$ was higher, than values previously reported for $N$. granulata, suggesting a stronger nutritional flexibility in the larvae used in the present study. Our results indicate significant intraspecific variability among separate populations, seasonal variation, and carryover effects of environmental conditions prevailing during the embryonic phase, all of which may affect the performance of the larval phase.

Keywords Crab larvae $\cdot$ Nutritional flexibility · Larval size $\cdot$ Argentina

\section{Introduction}

The estuarine crab Neohelice granulata Dana 1853 (Grapsoidea: Varunidae; formerly known as Chasmagnathus granulatus; for recent generic revision, see Sakai et al. 2006), is widely distributed in coastal regions of the southwestern Atlantic, ranging from Río de Janeiro, Brazil, to the Gulf of San José, Argentina. In temperate coastal salt-marshes in Argentina, this burrowing and semiterrestrial species can reach densities above $130 \mathrm{ind} / \mathrm{m}^{2}$ (Bas et al. 2005).

In a previous study (Bas et al. 2007), we observed that the average size and chemical composition of eggs and newly hatched larvae varied both during the reproductive 
season and between two populations living in ecologically contrasting habitats. In oceanic intertidal habitats near San Antonio (northern Patagonia), consistently larger eggs and larvae were produced, showing also a higher biomass (dry weight, lipid content), compared to those from a brackish coastal lagoon, Mar Chiquita (Province of Buenos Aires). Also, size and biomass of eggs and early larvae were significantly larger at the beginning of the reproductive season compared to those produced later.

In the present study, we tested the hypothesis that interand intrapopulational variation in egg size and larval biomass at hatching has implications for the nutritional flexibility of first-stage larvae. Additionally, we evaluated if the temperature prevailing during embryonic development has an effect on larval performance (measured as tolerance of food limitation).

\section{Methods}

\section{Study areas}

The coastal lagoon Mar Chiquita (MC) (collection site $37^{\circ} 45^{\prime} \mathrm{S}, 57^{\circ} 19^{\prime} \mathrm{W}$ ) shows great seasonal, daily, and local fluctuations in salinity, due to variations in tides, winds, and rainfalls. The primary productivity of the adjacent coastal waters is high, due to supply of organic nutrients derived from human activities. San Antonio Bay (SA) $\left(40^{\circ} 46^{\prime} \mathrm{S}\right.$, $64^{\circ} 50^{\prime} \mathrm{W}$ ), by contrast, is located in an arid coastal region with scarce rainfalls and no freshwater influx from rivers. Strong westerly winds prevail in this area, causing strong evaporation during the warm season. The average levels of salinity and temperature are higher than in the adjacent coastal waters, while the productivity is low (for further details, see Bas et al. 2007, and references cited therein).

\section{Collection and maintenance of crabs, experimental design}

In both populations, ovigerous females were collected at the beginning of the reproductive season (hereafter briefly referred to as "season") corresponding to each site (October 7 and November 26, 2002; MC and SA, respectively) and at the end of it, (January 27 and March 5, 2003, SA and MC, respectively). In MC, additional samples were taken also at the beginning of the following season (October 17, 2003).

Ovigerous females with eggs in an initial stage of embryonic development ( $>90 \%$ yolk, having passed through $<20 \%$ of embryogenesis; Bas and Spivak 2000) were selected from both populations and transported to the laboratory. Groups of ten individuals each were placed in plastic aquaria with filtered seawater (32 psu salinity), kept at LD 12:12, with constant air supply, at 18 or $27^{\circ} \mathrm{C}$, and fed every 3 days. When hatching began, females were put individually in aquaria (same conditions as before), and newly hatched larvae were collected. The time elapsed from an early embryonic stage until hatching was registered in each brood as an estimate of the duration of embryonic development, which can be compared with previous data (Bas 2001; Bas and Spivak 2000).

A sample of 20-30 newly hatched larvae was fixed in $4 \%$ formaldehyde for a later estimation of larval carapace volume, using the equation for an ellipsoid $\left(V=d^{2} \times\right.$ $D \times \pi / 6$; with $d=$ carapace width measured between the bases of the lateral spines, $D=$ carapace length taken from the base of the rostral spine to the posterior edge of the carapace).

Sixteen groups of 20 freshly hatched, actively swimming larvae each were selected from each brood for experimental determinations of the point-of-no-return (PNR) and the point-of-reserve-saturation (PRS, Anger 2001). The groups were kept separately in $100 \mathrm{ml}$ cultivation vials with filtered seawater (32 psu salinity), which were placed inside incubation chambers and kept at LD $12: 12$ and $20^{\circ} \mathrm{C}$. In daily intervals, water was changed and the larvae fed with freshly hatched Artemia sp. nauplii (except for starvation experiments).

In the present paper, larvae from females that had been incubated at 18 or $27^{\circ} \mathrm{C}$ are referred to as " $18^{\circ}$ larvae" and " $27^{\circ}$ larvae", respectively. Seasonally different collection times (beginning or end of the season) are referred to as "dates," and the time between hatching and the molt to the zoea II stage is referred as "stage duration."

\section{PNR and PRS experiments}

Nutritional flexibility was measured as median $\mathrm{PRS}_{50}$ and median $\mathrm{PNR}_{50}$. The $\mathrm{PRS}_{50}$ is the minimum initial feeding period allowing $50 \%$ of the larvae to accumulate enough reserves to complete the rest of the moulting cycle also in the absence of food, i.e., utilizing exclusively stored energy. The $\mathrm{PNR}_{50}$ is the maximum time of initial starvation allowing $50 \%$ of the larvae to recover and complete the moulting cycle after re-feeding (i.e., $50 \%$ of the larvae are irreversibly damaged and therefore doomed to die).

In the PNR experiments, from each hatch eight groups of 20 larvae each were starved for different periods (0-7 days), and then fed, until all of them had moulted or died. In the PRS experiment, from each hatch eight groups of 20 larvae each were initially fed for different periods ( $0-7$ days) and then deprived of food, until all of them had molted or died. The first treatment of each experiment (continuously fed and starved, respectively) represented a control group. In both experiments, mortality rates, and stage durations were registered for each brood at treatment. 
Data analysis

Standard statistical analyses were based on Zar (1996) and Underwood (1997). Normality was checked with normal plots and homoscedasticity with Cochran's test. Data of larval volume, stage duration, and from PNR and PRS experiments with MC larvae produced at the beginning of the two seasons were pooled for subsequent analyses, since no differences were detected when compared with $t$ tests.

Mortality data from all treatments of each brood in PNR and PRS experiments were fitted to a sigmoid doseresponse curve to obtain a value of $50 \%$ mortality which could be used to compare responses among broods $\left(\mathrm{PNR}_{50}\right.$ and PRS $_{50}$ values):

$M(\mathrm{t})=M_{0}+\left(M_{\mathrm{f}}-M_{0}\right) /\left\{1+10 \wedge\left[\left(P_{50}-t\right) \times\right.\right.$ Hillslope $\left.]\right\}$

where $M(\mathrm{t})$ is the number of dead larvae in the $\mathrm{t}$ feeding/ starvation period (for PRS and PNR, respectively); $M_{0}$ is the mortality of the control group; $M_{\mathrm{f}}$ is the asymptotic mortality when time increases; $P_{50}$ is the time when the survival was $50 \%$ of that of the control group (Anger 1987). Since very different velocities of response were observed in different broods, a sigmoid function with variable slope was used for fitting data instead of the constant slope function commonly used. The fitting obtained with this method was always good ( $R^{2}$ between 0.73 and 0.99 ).

Point-of-no-return and $\mathrm{PRS}_{50}$ values were compared with a three-way ANOVA with population, date, and prehatching temperature as factors. Stage durations in PSR and PNR experiments were compared separately for each population (because of heterogeneity of variances) using three-way ANOVAs, with days of feeding (1-7) or days of starvation (1-4 at MC, 1-5 at SA), date and pre-hatching temperature as factors. Regression lines for days of starvation or days of feeding vs. stage duration were compared between populations in PRS and PNR experiments.

No statistical analyses were performed for the comparison of the embryonic period among pre-hatching temperatures, populations, and dates because the day of egg-laying was in some broods estimated rather than precisely known.

\section{Results}

\section{Embryonic development}

The embryonic period averaged 14.7 days at $27^{\circ} \mathrm{C}$ versus 26.5 days at $18^{\circ} \mathrm{C}$ (pooled data from both populations). Development at $27^{\circ} \mathrm{C}$ was longer at the beginning than at the end of the reproductive season, while the opposite tendency occurred at $18^{\circ} \mathrm{C}$. No trends were observed when populations were compared (Fig. 1).

Larval size

Larval carapace volume ranged between 0.032 and $0.050 \mathrm{~mm}^{3}$ at SA and between 0.023 and $0.040 \mathrm{~mm}^{3}$ at MC. In both populations, the larvae were significantly larger at the beginning than at the end of season. Differences in larval body size observed after embryonic development at different pre-hatching temperatures were not significant. However, the interaction among the three factors was significant (Table 1).

Stage duration

\section{Control groups}

The stage duration of continuously fed zoea I larvae was significantly shorter at SA than at MC, and in both populations it was shorter at the beginning of the season compared to the end (Fig. 2a, b, days 4-7; Fig. 2c, d, day $0 ; P<0.0001$ for both factors). The pre-hatching temperature, on the other hand, had no significant effect $(P=0.23)$, and no interactions occurred between temperature and other factors (all $P>0.4$ ). Significant differences persisted when larval volume was included as a covariate $(P<0.0001, P=0.001$; for factors population and time, respectively).

\section{PRS experiments}

In larvae from MC, stage duration was affected by the feeding period and date (Fig. 2a). Pre-hatching temperature had no significant effect, and no interactions among factors were found (Table 2). An a posteriori test showed that the stage duration of larvae fed initially for only one day was

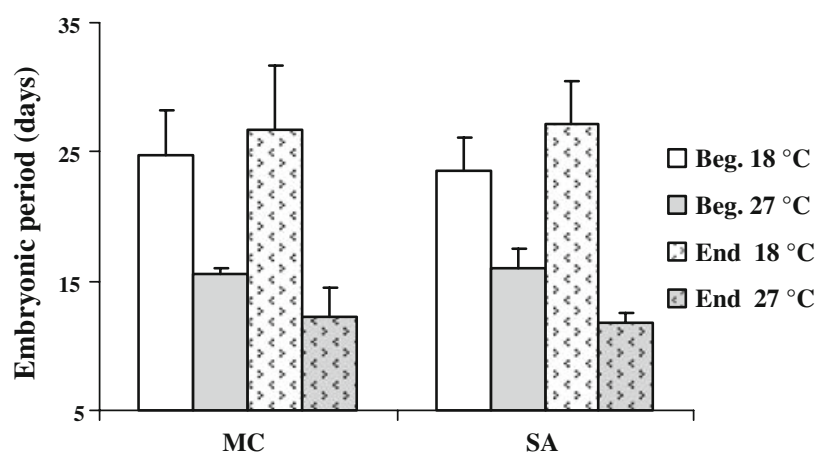

Fig. 1 Neohelice granulata. Time (mean $+\mathrm{SD}$ ) elapsed from egg extrusion to hatching in 63 broods from Mar Chiquita $(M C)$ and San Antonio ( $S A)$, at different pre-hatching temperatures (18 and $27^{\circ} \mathrm{C}$ ), at the beginning (beg.) and end of the reproductive season 
Table 1 Neohelice granulata. Three-way ANOVA to test the effect of population (Mar Chiquita and San Antonio), time within the reproductive season (dates: beginning and end) and pre-hatching temperature $\left(18\right.$ and $\left.27^{\circ} \mathrm{C}\right)$ on zoea I volume

\begin{tabular}{|c|c|c|c|c|c|c|}
\hline Factor & $\begin{array}{l}d f \\
\text { Effect }\end{array}$ & $\begin{array}{l}\text { MS } \\
\text { Effect }\end{array}$ & $\begin{array}{l}d f \\
\text { Error }\end{array}$ & $\begin{array}{l}\text { MS } \\
\text { Error }\end{array}$ & $F$ & $\begin{array}{l}P \text { - } \\
\text { level }\end{array}$ \\
\hline Population (P) & 1 & 872.85 & 39 & 10.89 & 80.1 & 0.000 \\
\hline $\begin{array}{l}\text { Temperature } \\
\text { (T) }\end{array}$ & 1 & 34.41 & 39 & 10.89 & 3.15 & 0.083 \\
\hline Date (D) & 1 & 354.91 & 39 & 10.89 & 32.5 & 0.000 \\
\hline $\mathrm{P} \times \mathrm{T}$ & 1 & 0.29 & 39 & 10.89 & 0.02 & 0.86 \\
\hline$P \times D$ & 1 & 4.27 & 39 & 10.89 & 0.39 & 0.53 \\
\hline $\mathrm{T} \times \mathrm{D}$ & 1 & 0.02 & 39 & 10.89 & 0.002 & 0.96 \\
\hline $\mathrm{P} \times \mathrm{T} \times \mathrm{D}$ & 1 & 63.39 & 39 & 10.89 & 5.8 & 0.02 \\
\hline
\end{tabular}

Significant values in bold

significantly longer that of larvae fed for two or more days (Tukey HSD test, $P<0.001$ ). A similar result was found at $\mathrm{SA}$, but a significant interaction among the three factors was found in this case (Fig. 2b; Table 2).

\section{PNR experiments}

In all experimental conditions there was a nearly linear relationship between the stage duration and the duration of the initial period of starvation (Fig. 2c, d). At MC, the stage duration differed significantly not only among starvation treatments (1-4 days), but also between dates within the reproductive period; the interaction between both factors was also significant. Pre-hatching temperature had not effect on stage duration in starved larvae, independent of other factors (Fig. 2c; Table 3). At SA, the relation between stage duration and the time of starvation (1-5 days), dates, and pre-hatching temperature was similar to that in larvae from MC (Fig. 2d; Table 3). Nevertheless, in this case the interaction among all factors was significant (Table 3).

Survival

\section{PRS experiments}

At MC, continuously starved larvae did not moult to the zoea II. Mortality in larvae that were initially fed for only 1 day was high, but variable among clutches (20-100\%; Fig. 3a). The level of mortality in larvae fed for two or more days was generally lower and independent of the duration of the feeding period (Fig. 3a). The $\mathrm{PRS}_{50}$ varied among clutches from 0.76 to 2.33 days. At SA, two continually starved larvae (out of 540) molted after 5.5 days to the zoea II (Fig. 2b). Mortality of larvae fed for one or more days was generally low and independent of the feeding period (Fig. 3b). The $\mathrm{PRS}_{50}$ varied among clutches between 0.19 and 1.92 days.

A three-way ANOVA showed significant differences in $\mathrm{PRS}_{50}$ values between populations and dates, but not between pre-hatching temperatures; interactions were not significant (Fig. 3c, d; Table 4). The time necessary to accumulate enough reserves for moulting was shorter in zoeae produced at the beginning of the season, and it was always shorter at SA than at MC.

Differences in the $\mathrm{PRS}_{100}$ were not significant between dates or temperatures for each population $(P=0.07$, average 2.77 days in $\mathrm{MC} ; P=0.19$, average 1.46 days in SA), but between populations $(P<0.001$; Fig. $3 \mathrm{c}, \mathrm{d})$. When the $\mathrm{PRS}_{50}$ observed at each condition is related to the corresponding stage duration in the control group, one can say that $50 \%$ of the larvae produced at the beginning of the season completed sufficient energy reserves for later
Fig. 2 Neohelice granulata. Stage duration of Zoea I (time from hatching to molting) in relation to food limitation in Mar Chiquita $(M C)$ and San Antonio $(S A)$. a, b Point of Reserve Saturation (PRS) experiments; c, d Point of no Return $(P N R)$ experiments; beg., end beginning and end of the reproductive season; $18,27^{\circ} \mathrm{C}$ pre-hatching temperatures

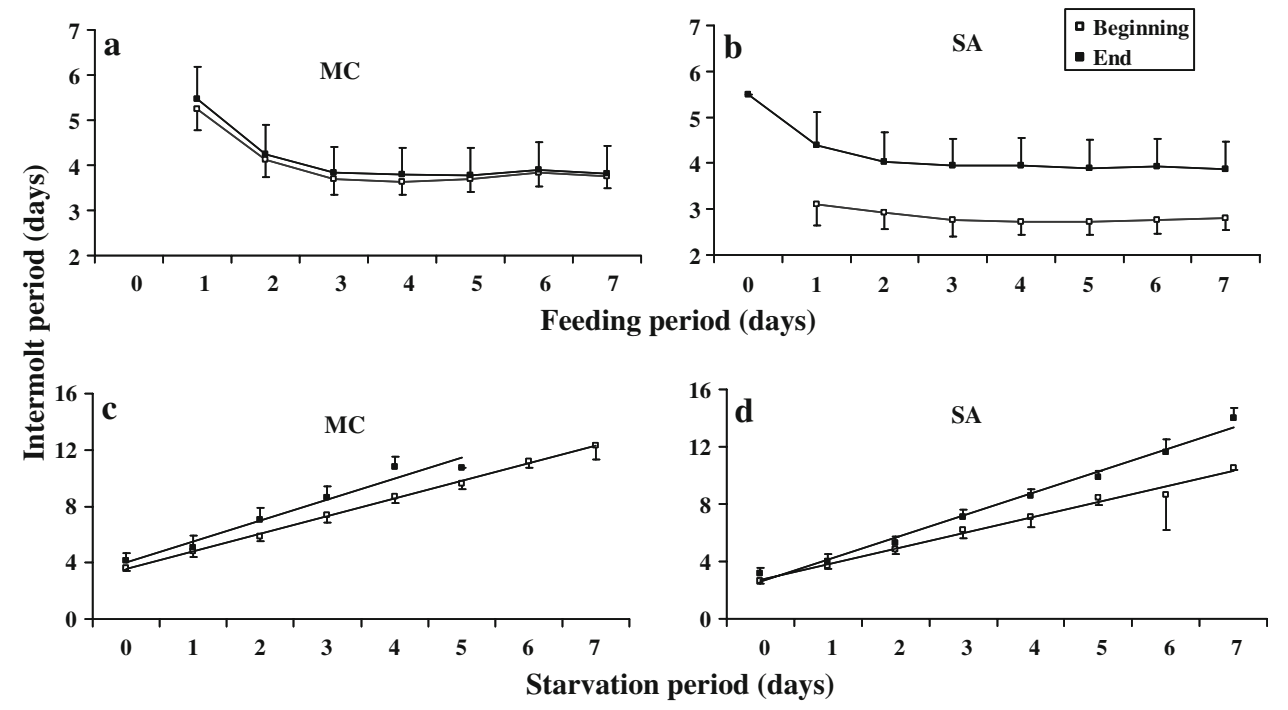


Table 2 Neohelice granulata. Three-way ANOVA to test the effect of time within the reproductive season (dates: beginning and end), prehatching temperatures (18 and $27^{\circ} \mathrm{C}$ ), and number of days of initial feeding, and their interactions, on the stage duration of zoea I from Mar Chiquita and San Antonio

*Significant values of $P(\alpha=0.05)$

Table 3 Neohelice granulata. Three-way ANOVA to test the effect of time within the reproductive season (dates: beginning and end), prehatching temperatures (18 and $27^{\circ} \mathrm{C}$ ), and number of days days of initial starvation, and their interactions, on the stage duration of zoeae I from Mar Chiquita and San Antonio

*Significant values of $P(\alpha=0.05)$

\begin{tabular}{lllllrl}
\hline Factor & $d f$ Effect & MS Effect & $d f$ Error & MS Error & $F$ & $P$-level \\
\hline Mar Chiquita & & & & & & \\
Date (D) & 1 & 1.487 & 56 & 0.284 & 5.235 & $0.025^{*}$ \\
Temperature (T) & 1 & 0.086 & 56 & 0.284 & 0.304 & 0.583 \\
Days of feeding (F) & 2 & 8.798 & 56 & 0.284 & 30.974 & $0.000^{*}$ \\
D $\times$ T & 1 & 0.072 & 56 & 0.284 & 0.256 & 0.614 \\
D $\times$ F & 2 & 0.232 & 56 & 0.284 & 0.820 & 0.445 \\
F $\times$ T & 2 & 0.453 & 56 & 0.284 & 1.597 & 0.211 \\
D $\times$ F $\times$ T & 2 & 0.358 & 56 & 0.284 & 1.262 & 0.290 \\
& & & & & & \\
San Antonio & 1 & 14.294 & 67 & 0.131 & 108.333 & $0.000^{*}$ \\
Date (D) & 1 & 0.021 & 67 & 0.131 & 0.161 & 0.688 \\
Temperature (T) & 2 & 3.068 & 67 & 0.131 & 23.258 & $0.000^{*}$ \\
Days of feeding (F) & 1 & 1.440 & 67 & 0.131 & 10.913 & $0.001^{*}$ \\
D $\times$ T & 2 & 0.584 & 67 & 0.131 & 4.429 & $0.015^{*}$ \\
D $\times$ F & 2 & 0.876 & 67 & 0.131 & 6.640 & $0.002^{*}$ \\
F $\times$ T & 2 & 0.590 & 67 & 0.131 & 4.474 & $0.014^{*}$ \\
D $\times$ F $\times$ T & & & & &
\end{tabular}

\begin{tabular}{llcllrl}
\hline Factor & $d f$ Effect & MS Effect & $d f$ Error & MS Error & $F$ & $P$-level \\
\hline Mar Chiquita & & & & & & \\
Date (D) & 1 & 29.082 & 73 & 0.413 & 70.328 & $0.000^{*}$ \\
Temperature (T) & 1 & 0.003 & 73 & 0.413 & 0.008 & 0.926 \\
Days of starvation (S) & 3 & 82.789 & 73 & 0.413 & 200.204 & $0.000^{*}$ \\
D $\times$ T & 1 & 0.428 & 73 & 0.413 & 1.035 & 0.312 \\
D $\times$ S & 3 & 2.726 & 73 & 0.413 & 6.594 & $0.000^{*}$ \\
S $\times$ T & 3 & 0.895 & 73 & 0.413 & 2.165 & 0.099 \\
D $\times$ S $\times$ T & 3 & 0.694 & 73 & 0.413 & 1.680 & 0.178 \\
& & & & & & \\
San Antonio & & & & & & \\
Date (D) & 1 & 21.883 & 104 & 0.229 & 95.527 & $0.000^{*}$ \\
Temperature (T) & 1 & 0.234 & 104 & 0.229 & 1.022 & 0.314 \\
Days of starvation (S) & 4 & 82.697 & 104 & 0.229 & 360.997 & $0.000^{*}$ \\
D $\times$ T & 1 & 0.471 & 104 & 0.229 & 2.057 & 0.154 \\
D $\times$ S & 4 & 1.745 & 104 & 0.229 & 7.618 & $0.000^{*}$ \\
S $\times$ T & 4 & 0.017 & 104 & 0.229 & 0.077 & 0.989 \\
D $\times$ S $\times$ T & 4 & 0.645 & 104 & 0.229 & 2.817 & $0.028^{*}$ \\
\hline
\end{tabular}

development to ecdysis in absence of food, as soon as $30.5 \%$ (MC) or $23.1 \%$ (SA) of the stage duration had elapsed under favorable feeding conditions. The corresponding percentage values observed at the end of the season were $41 \%(\mathrm{MC})$ and $32.4 \%$ (SA), respectively.

\section{PNR experiments}

At MC, $15 \%$ of the larvae obtained at the beginning of the season, after embryonic incubation at $27^{\circ} \mathrm{C}$, survived and molted after 6 days of starvation, $5 \%$ after 7 days. In all other experimental conditions, no larvae survived 7 days of starvation, and only two individuals $(0.7 \%)$ survived after 6 days of starvation (Fig. 4a). In larvae from SA, the survival after 6 and 7 days of starvation was similar in all experimental conditions (15 and 4.6\%, respectively, Fig. 4b).

A three-way ANOVA showed that differences in the $\mathrm{PNR}_{50}$ were significant between populations and prehatching temperatures, but not between dates; the interactions between the three factors were significant (Table 5). The average $\mathrm{PNR}_{50}$ values of larvae hatched at $18^{\circ} \mathrm{C}$ were lower than those that hatched at $27^{\circ} \mathrm{C}$ (MC $2.52 \pm 0.92$ 
Fig. 3 Neohelice granulata. a, b Mortality in the Point of Reserve Saturation (PRS) experiments (mean percentage $+\mathrm{SD}$ of all broods for each condition);

c, d Sigmoid curves fitted to all $\mathrm{PRS}_{50}$ estimated for each brood. MC Mar Chiquita, SA San Antonio
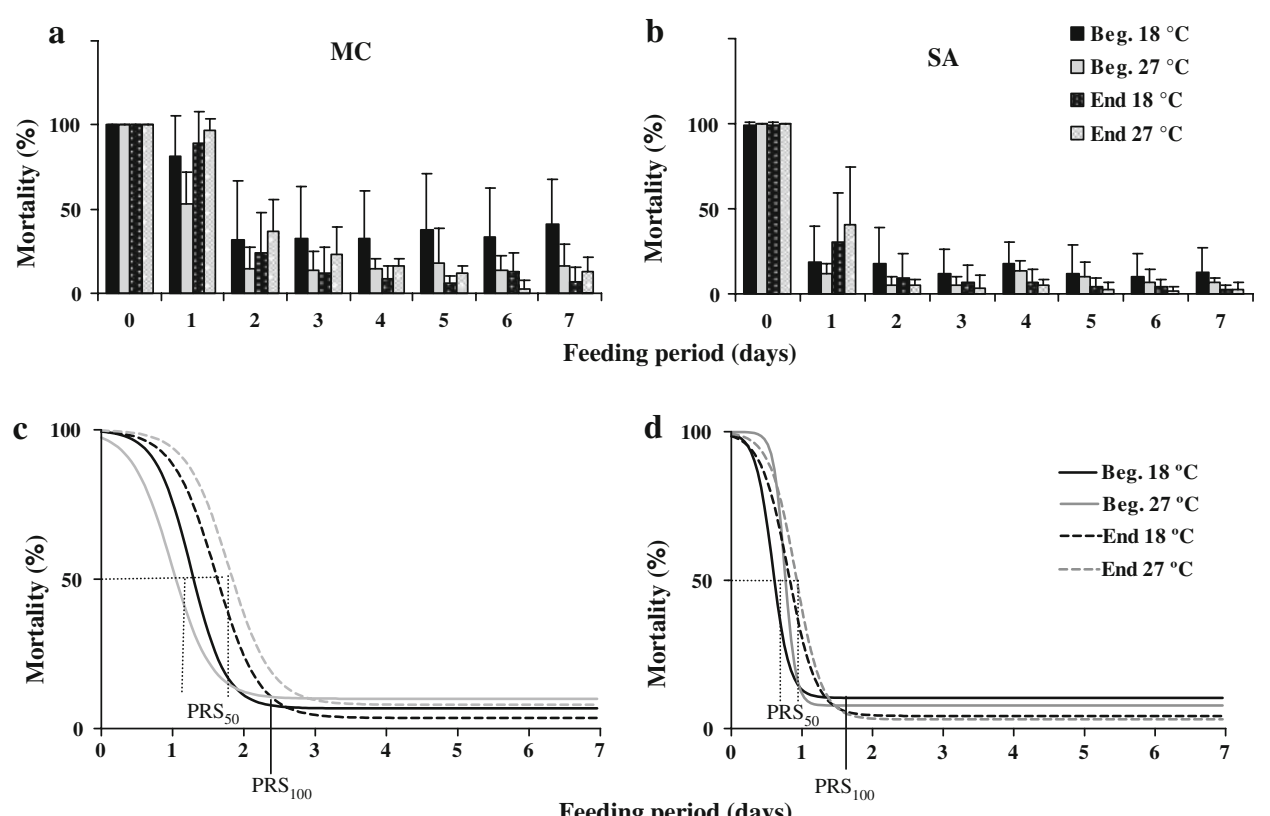

Feeding period (days)
Table 4 Neohelice granulata. Three-way ANOVA to test the effect of population (Mar Chiquita and San Antonio), prehatching temperature (18 and $27^{\circ} \mathrm{C}$ ) and time within the reproductive season (date; beginning and end) on zoea I $\mathrm{PRS}_{50}$

Significant values in bold

Fig. 4 Neohelice granulata. a, b Mortality in the Point of no Return $(P N R)$ experiments (mean percentage $+\mathrm{SD}$ of all broods for each condition); c, $\mathbf{d}$ sigmoid curves fitted to all $\mathrm{PNR}_{50}$ estimated for each brood. MC Mar Chiquita, SA San Antonio

\begin{tabular}{lllllcl}
\hline Factor & $d f$ & MS & $d f$ & MS & $F$ & $P$-level \\
& Effect & Effect & Error & Error & & \\
\hline Population (P) & 1 & 3.497 & 39 & 0.135 & 25.79 & $\mathbf{0 . 0 0 0 0 1}$ \\
Temperature (T) & 1 & 0.000 & 39 & 0.135 & 0.000 & 0.9937 \\
Date (D) & 1 & 2.394 & 39 & 0.135 & 17.65 & $\mathbf{0 . 0 0 0 1 4}$ \\
$\mathrm{P} \times \mathrm{T}$ & 1 & 0.003 & 39 & 0.135 & 0.022 & 0.880 \\
$\mathrm{P} \times \mathrm{D}$ & 1 & 0.137 & 39 & 0.135 & 1.015 & 0.319 \\
$\mathrm{~T} \times \mathrm{D}$ & 1 & 0.002 & 39 & 0.135 & 0.018 & 0.891 \\
$\mathrm{P} \times \mathrm{T} \times \mathrm{D}$ & 1 & 0.281 & 39 & 0.135 & 2.074 & 0.157 \\
\hline
\end{tabular}
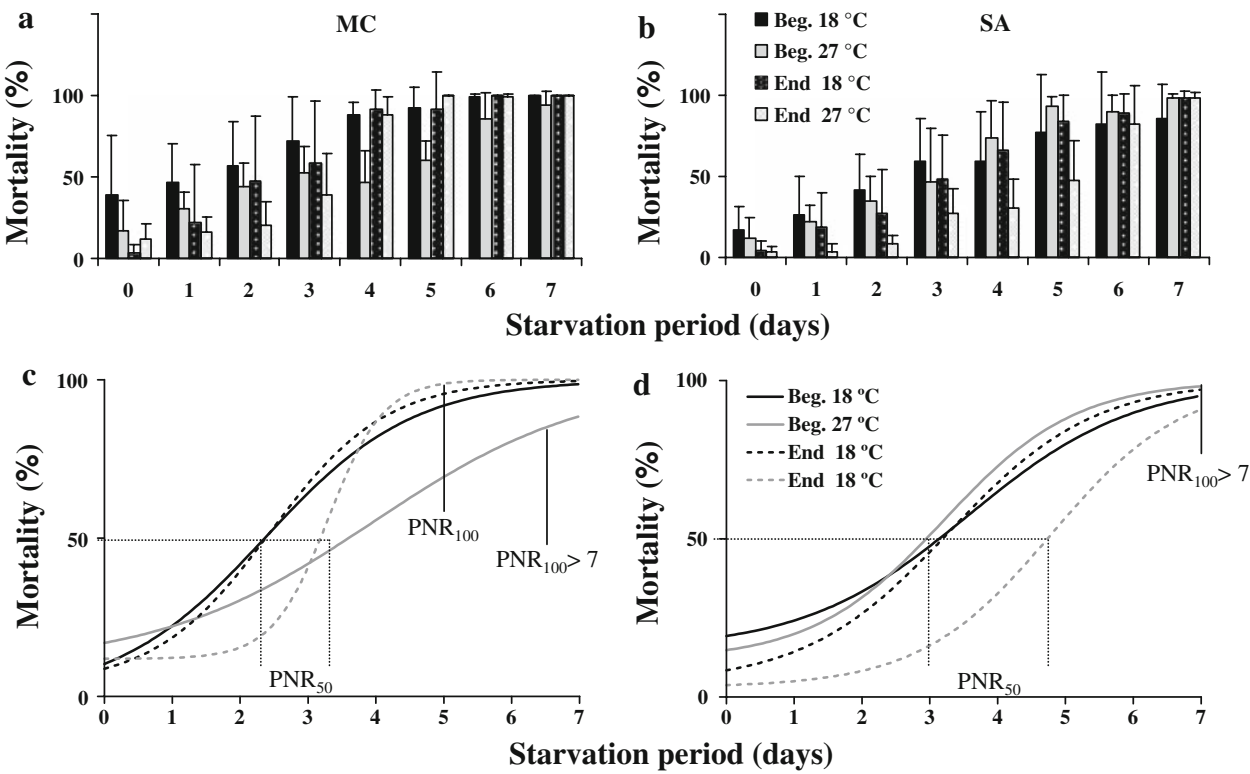
Table 5 Neohelice granulata. Three-way ANOVA to test the effect of population (Mar Chiquita and San Antonio), prehatching temperature (18 and

$27^{\circ} \mathrm{C}$ ) and time within the reproductive season (date; beginning and end) on zoea I $\mathrm{PNR}_{50}$

Significant values in bold

\begin{tabular}{lllllll}
\hline Factor & $d f$ Effect & MS Effect & $d f$ Error & MS Error & $F$ & $P$-level \\
\hline Population (P) & 1 & 3.7269 & 40 & 0.8785 & 4.2423 & $\mathbf{0 . 0 4 5 9 7}$ \\
Temperature (T) & 1 & 7.6229 & 40 & 0.8785 & 8.6770 & $\mathbf{0 . 0 0 5 3 5}$ \\
Date (D) & 1 & .04430 & 40 & 0.8785 & 0.5043 & 0.48172 \\
$\mathrm{P} \times \mathrm{T}$ & 1 & 0.5854 & 40 & 0.8785 & 0.6664 & 0.4191 \\
$\mathrm{P} \times \mathrm{D}$ & 1 & 1.7349 & 40 & 0.8785 & 1.9748 & 0.1676 \\
$\mathrm{~T} \times \mathrm{D}$ & 1 & 0.5101 & 40 & 0.8785 & 0.5807 & 0.4504 \\
$\mathrm{P} \times \mathrm{T} \times \mathrm{D}$ & 1 & 5.8788 & 40 & 0.8785 & 6.6917 & $\mathbf{0 . 0 1 3 4}$ \\
\hline
\end{tabular}

days and $3.54 \pm 0.78$ days; SA $3.44 \pm 1.20$ days and $4.38 \pm 1.06$ days, at 18 and $27^{\circ} \mathrm{C}$ respectively). At $\mathrm{MC}$, $27^{\circ} \mathrm{C}$ larvae differed clearly from $18^{\circ} \mathrm{C}$ larvae (Fig. 4c). $27^{\circ} \mathrm{C}$ larvae from SA were only at the end of the season clearly more resistant to starvation (Fig. 4d). The PNR 100 was in many cases higher than the experimental period of 7 days, so that no exact data were obtained for this index (Fig. 4c, d).

\section{Discussion}

Size, biomass, and biochemical composition of eggs and larvae are highly relevant life-history traits which are under selection acting on two successive generations. Large size and biomass are presumed to enhance the chance for offspring survival, increasing its abilities to compete for food and/or to resist starvation. Variation in those traits may have a genetic base, or it may represent a plastic response to variations in environmental conditions, being considered as adaptive if it increases the fitness of embryos or larvae. Nevertheless, only few studies have examined consequences of variation in progeny size for fitness (Fox and Czesak 2000).

The biotic and abiotic environment establishes the context where variation in individual fitness is generated. In addition, they have an important influence in the generation of phenotypes throughout development, which are themselves under selection (Kaplan and Phillips 2006). Such effects on early developmental stages may affect the individual performance in other phases of the life history through carry-over effects (Giménez, 2004).

The eggs of $N$. granulata are exposed to a much broader range of temperatures than the larvae. The intertidal environment, were the semiterrestrial adults live, show strong seasonal, and daily variations (up to $10^{\circ} \mathrm{C}$ ) in air temperature (Spivak et al. 1994). As in all poikilotherm animals, the duration of the embryonic period increases with decreasing temperature. At low temperature $\left(18^{\circ} \mathrm{C}\right)$, the largest eggs (showing also a higher lipid content), which were in both populations produced at the beginning of the reproductive season (Bas et al. 2007), developed faster than the smaller eggs produced at the end of the season. The opposite trend, however, was observed when embryonic development took place at a high temperature $\left(27^{\circ} \mathrm{C}\right)$.

The temperature prevailing during the period of embryonic development may affect larval size in different ways, depending on the temperature range considered, and possibly on a species climatic-geographical distribution. In a subtropical mud crab, Rhithropanopeus harrisii, for example, the zoea I was heavier when the embryos had been incubated at a higher experimental temperature, while newly hatched larvae of a majid crab from temperatesubarctic regions, Chionoecetes opilio, were smaller (Laughlin Jr and French 1989; Webb et al. 2006). In $N$. granulatus, larval size was not significantly affected by variation in pre-hatching temperature in the studied range.

The ability of larvae to moult, after a limited initial feeding period, even in the absence of food, was correlated with the respective stage duration in continuous presence of food: faster developing larvae get along with a shorter initial feeding period (smaller $\mathrm{PRS}_{50}$ ). The proportion of the molting cycle corresponding to the $\mathrm{PRS}_{50}$ varied between the beginning and end of the season, suggesting that the regulation of both processes is independent. This variability in the $\mathrm{PSR}_{50}$ /stage ratio has not been previously reported in other species.

In the North Sea, where water temperature varies seasonally by ca. $15^{\circ} \mathrm{C}$, Paschke et al. (2004) found that the larvae of a shrimp, Crangon crangon, produced in winter and spring had, at identical rearing conditions, shorter moulting cycles than the larvae released in summer. The authors concluded that this effect should be advantageous under cold conditions, as it may partially offset the developmental deceleration caused by low temperatures. In the study area of $N$. granulata, temperature differences between the beginning and the end of the reproductive season did not exceed $7^{\circ} \mathrm{C}$; nevertheless, the above explanation may apply also to this species because larval metabolism is very sensitive to changes in temperature (Ismael et al. 1997).

Giménez and Anger (2001) found that the exposure of females to different salinities elicited variations in size and development of embryos and larvae of $N$. granulata. 
Embryos and larvae showed larger size and biomass when embryonic incubation occurred at 15 psu. Also, larvae produced at 15 or $20 \mathrm{psu}$ had lower $\mathrm{PRS}_{50}$ values, and their stage duration was shorter, than in larvae from $32 \mathrm{psu}$ (Giménez 2002). The frequent occurrence of low salinities in winter and spring at MC may thus be responsible for larger size and biomass of eggs and larvae, as well as for lower $\mathrm{PRS}_{50}$ values in the zoea I, observed at the beginning of the reproductive season. On the other hand, the same seasonal pattern occurred also at SA, where it cannot be attributed to low salinities in winter.

A developmental delay due to starvation periods following an initial period of feeding is normally weak and may not be a general phenomenon (Anger 1987). In $N$. granulata, we detected this effect only in zoeae that were fed for a single day and then starved until moulting or death, while larvae that were initially fed for longer periods showed no significant developmental delay.

When food is initially absent, followed by a period of feeding, the larvae may suffer an irreversible damage and reach their PNR. For larvae of $N$. granulata Giménez (2002) reported PNR $_{50}$ values below 3 days, which represented less than $50 \%$ of the stage duration in continuous presence of food (6 days). In natural populations, however, larval starvation tolerance may be higher: in the present study, $\mathrm{PNR}_{50}$ values observed at MC varied from 65 to $>100 \%$ of the stage duration, and in larvae from SA this index was always $>100 \%$. These $\mathrm{PNR}_{50}$ values are actually higher than those reported from decapod species that have been considered as fairly resistant to starvation, e.g., Carcinus maenas (Dawirs 1984) and Crangon crangon (Paschke et al. 2004).

In a previous study (Bas et al. 2007), we suggested that differences in the size of eggs and larvae of $N$. granulata populations living at SA and MC could be correlated with differential productivity in the waters where larval development occurs. Comparably low plankton productivity at SA and in the adjacent waters of the Gulf of San Matías (Carreto et al. 1974) should select for larger larvae with a stronger starvation tolerance, including an enhanced ability to accumulate within a short time sufficient energy reserves to develop subsequently also under poor nutritional conditions, and even in complete absence of food. Our present results corroborate this hypothesis. Nevertheless, it is not entirely clear which are the relationships between egg size, content of organic matter, and larval development in highly productive and food-limited conditions, and certainly more studies are necessary to understand the role of temperature effects that may modify the PNR in larvae.

Neohelice granulata, as probably most decapod crustacean species in temperate coastal environments, can adapt its physiological response to variations in environmental conditions throughout its life cycle, modifying even its pattern of larval development. Consequently, the effect of each factor must be evaluated considering also the individual's origin and previous experience. Long-term and multi-factorial studies will be necessary to understand the scope of carry-over effects in successive phases of the life cycle, before trait-mediated effects can be included in benthic models, defining the quality of settling larvae and early juveniles (Giménez 2004).

Acknowledgments This study was funded by grants from the Universidad de Mar del Plata (15/E149) and the Consejo Nacional de Investigaciones Científicas y Técnicas de la República Argentina (CONICET; PIP 0838/98) conferred to EDS and by a postdoctoral fellowship from CONICET conferred to CCB.

\section{References}

Anger K (1987) The $D_{0}$ threshold: a critical point in the larval development of decapod crustaceans. J Exp Mar Biol Ecol 108: $15-30$

Anger K (2001) The biology of decapod crustacean larvae. Crustacean issues 14. A A Balkema Publishers, Lisse

Bas C (2001) Efecto de la salinidad y la temperatura sobre el ciclo de vida de cangrejos estauriales (Decapoda, Grapsidae). Tesis de Doctorado, Universidad Nacional de Mar del Plata

Bas C, Spivak E (2000) Effect of salinity on embryos of two Southwestern Atlantic estuarine grapsid crab species cultured in vitro. J Crust Biol 20:647-656

Bas C, Luppi T, Spivak E (2005) Population structure of the South American estuarine crab, Chasmagnathus granulatus (Brachyura: Varunidae) near the southern limit of its geographical distribution: comparison with northern populations. Hydrobiologia 537:217-228

Bas C, Spivak E, Anger K (2007) Seasonal and interpopulational variability in fecundity, egg size, and elemental composition (CHN) of eggs and larvae in a grapsoid crab, Chasmagnathus granulatus. Helgol Mar Res 61:225-237

Carreto J, Verona C, Casal A, Laborde M (1974) Fitoplancton, pigmentos y condiciones ecológicas del golfo San Matías. III. An Com Invest Cient Prov Bs As. Informe 10, Publicaciones de la Comisión de Investigaciones Científicas de la provincia de Buenos Aires (CIC), pp 49-76

Dawirs R (1984) Influence of starvation on larval development of Carcinus maenas L. (Decapoda: Portunidae). J Exp Mar Biol Ecol 80:47-66

Fox C, Czesak M (2000) Evolutionary ecology of progeny size in arthropods. Annu Rev Entomol 45:341-369

Giménez L (2002) Effects of prehatching salinity and initial larval biomass on survival and duration of development in the zoea 1 of the estuarine crab, Chasmagnathus granulata, under nutritional stress. J Exp Mar Biol Ecol 270:93-110

Giménez L (2004) Marine community ecology: the importance of trait-mediated effects propagating through complex life cycles. Mar Ecol Prog Ser 283:303-310

Giménez L, Anger K (2001) Relationships among salinity, egg size, embryonic development, and larval biomass in the estuarine crab Chasmagnathus granulata Dana, 1851. J Exp Mar Biol Ecol 260:241-257

Ismael D, Anger K, Moreira G (1997) Influence of temperature on larval survival, development and respiration in Chasmagnathus granulata (Crustacea Decapoda). Helgoländer Meeresunters 51:463-475 
Kaplan R, Phillips P (2006) Ecological and developmental context of natural selection: maternal effects and thermally induced plasticity in the frog Bombina orientalis. Evolution 60:142-156

Laughlin R Jr, French W (1989) Interactions between temperature and salinity during brooding on subsequent zoeal development of the mud crab Rhithropanopeus harrisii. Mar Biol 102:377-386

Paschke K, Gebauer P, Buchholz F, Anger K (2004) Seasonal variation in starvation resistance of early larval North Sea shrimp Crangon crangon (Decapoda: Crangonidae). Mar Ecol Prog Ser 279:183-191

Sakai K, Türkay M, Yang SL (2006) Revision of the Helice/ Chasmagnathus complex. (Crustacea: Decapoda: Brachyura). Abh Senckenberg Naturforsch Ges 565 Schweizerbart, Stuttgart
Spivak E, Anger K, Luppi T, Bas C, Ismael D (1994) Distribution and habitat preferences of two grapsid crab species in Mar Chiquita lagoon (Province of Buenos Aires, Argentina). Helgoländer Meeresunters 48:59-78

Underwood A (1997) Experiments in ecology. Cambridge University Press, Cambridge

Webb J, Eckert G, Shirley T, Tamone S (2006) Changes in zoeae of the snow crab, Chionoecetes opilio, with variation in incubation temperature. J Exp Mar Biol Ecol 339:96-103

Zar J (1996) Biostatistical analysis, 3rd edn. Prentice Hall, Upper Saddle River 